Graça D ruck 1

Tânia Franco 1

1 Centro de Recursos H umanos e D epartamento de Sociologia da Faculdade de Filosofia e Ciências H umanas, UFBA Rua Caetano M oura 99, 1 subsolo, 40223-360, Federação Salvador, BA. druck@ufba.br

taniafranc@uol.com.br

\title{
A Alca e as principais implicações para o trabalho e a saúde dos trabalhadores
}

\author{
The FTAA and the main consequences \\ for work and worker's health
}

Abstract This article analyses the FTAA in the globalization and newliberalism hegemony context. It approachs its implications considering N AFTA example, in development since 1994, whose results evidence a labor process, environment conditions and workers's health precarization. The flexibilization and disregulation of the rights, of the labor protection, health and environment legislation are strategys being used by greats capitalists grups in defense of capital free mobility. Therein, the FTAA means a synthesis of globalization process. In the Brazilian case, the work, the health and the environment have been deeply degraded in the last 10 years, as results of the flexibilization. The possibility of FTAA represents the intensification of this process, that will implicate a social regression that has no precedence. $N$ everthel ess, this article concludes that the anti-globalization movements, the international foruns, the continental and intercontinentals conferences, the network of against-powers, denote to be possible another A merica and another World.

Key words FTAA, W ork, Health, Environment, Flexibilization, Precarization
Resumo 0 artigo faz uma análise da Alca no contexto de gl obalização e de hegemonia neoliberal. A borda suas possí vei s implicações à luz do N afta, em curso desde 1994, cujos resultados evidenciam um processo de precarização do trabalho, das condições ambientais e de saúde dos trabalhadores. A flexibilização e a desregulamentação dos di reitos, das legislações de proteção ao emprego, à saú de e ao mei o ambiente são estratégias cada vez mais utilizadas pelos grandes grupos capitalistas na defesa da livre mobilidade dos capitais. A Alca representa uma síntese do processo de globalização. N o caso brasileiro, as dimensões do trabalho e (des) emprego, da saúde e do ambi ente têm sido for temente degradadas nos úl ti mos 10 anos, como resultado da desregulamentação e da flexibilização. A possibilidade da Alca representa não só a continuidade desse processo, mas o seu aprofundamento num patamar que levará a uma regressão social sem precedentes. $\mathrm{N}$ o entanto, conclui-se que as respostas dos movi mentos antiglobalização, os fóruns setoriais e internacionais, as conferências, as redes de contrapoderes, hoje nos mais diferentes países e regi ões do mundo, indicam ser possível uma outra América, um outro mundo.

Palavras-chave Alca, Trabalho, Saúde, M eio ambiente, Flexibilização, Precarização 


\section{A Área de Livre Comércio das Américas (Alca): um rápido histórico}

Em dezembro de 1994, líderes de 34 países das A méricas do Norte, Central, do Sul e do Caribe, reunidos na la Cúpula das Américas, em M iami, nos EUA, atendendo ao chamado do então presidente dos EU A Bill Clinton, Iançaram a proposta da Alca. N essa reunião, o presidente norte-americano propôs-se a realizar um sonho do anterior presidente George Bush. Esse sonho era criar um acordo de livre comérci o que se esten desse desde o A lasca ( norte do Canadá) até a Terra do Fogo ( sul da Argenti na). Seria um acordo que unisse a economia do H emisfério, aumentasse a integração social e política entre os países e se baseasse no mesmo modelo de livre comércio que éo N AFTA (Para entender a Alca, 2002).

A pós o seu lançamento, mais dois encontros da mesma natureza ( 2 a e $3 a$ Cúpula das A méricas) foram realizados em 1998 e 2001, estando prevista para abril de 2003 a 4a reunião da Cúpula das Américas. Além disso, ocorreram seis reuniões ministeriais, com a participação de ministros responsáveis pelo comércio dos países americanos. U ma dessas reuniões, realizada em 1997, ocorreu no Brasil, em Belo H orizonte.

$N$ esses fóruns foram se constituindo alguns organismos para avançar as propostas de negociações do A cordo. Já em 1998, criouse um Comitê de Negociações Comerciais $(\mathrm{CNC})$, formado pelos representantes da área de Comércio de cada país (ministros ou viceministros), e se constituíram nove Grupos de Trabalho: serviços ( educação, saúde ...); investimento; contratos públicos; acesso ao mercado; agricultura; direitos da propriedade intelectual; subsídios, antidumping e direitos de compensação; política de competição; resolução de disputas.

Esses comitês e grupos de trabal ho vêm se reunindo desde então, sempre com a exclusiva participação de representantes-membros de governos (executivos), sem qualquer interferência de outros poderes da sociedade. A participação dos parlamentos está prevista somente no momento de ratificação do acordo final, que deverá ter início em 2005. No entanto, o parlamento americano tem desempenhado um papel importante nas negociações dos termos do acordo, representando os interesses das gran des empresas norte-americanas, cujas pressões e lobbies têm influenciado decisivamente as definições, dentre elas, a própria antecipação do início da Alca, já para 2003, conforme noticiado pela imprensa. $M$ ais recentemente, no pós 11 de setembro, o governo Bush obteve do Congresso a Trade Promotion Authorithy - fast track ou "via rápida" - , que dá poder ao Executivo de negociar emendas comerciais sem que possam ser examinadas e alteradas pelo legislativo. $M$ ais do que isso, o Congresso definiu al gumas exigências e, dentre elas, apressar as negociações na Organização Mundial do Comércio (OMC) e na Alca, na direção de reforçar o protecionismo norte-americano em todas as áreas, na defesa dos "interesses nacionais" que, para os atuais dirigentes dos EU A, representam os interesses de todas as Américas.

Assim, a Alca pretende reunir 34 países, que congregam uma população de $800 \mathrm{mi}$ Ihões de pessoas. A penas um país está fora: Cuba, que sofreria com a implantação da Alca um isolamento maior ainda, tendo em vista a existência de uma área de "livre comércio" dirigida e controlada pela maior potência do mundo, nada menos do que o país que decretou o boicote econômico e político a Cuba, desde a revolução: os EUA.

A gritante desigualdade entre os países participantes da Alca pode ser constatada por um dos principais indicadores de produção de riquezas: o Produto Interno Bruto (PIB), que soma o valor de $U$ \$11 trilhões nos 34 países. Desse total, os EUA detêm $76,2 \%$, que, somados aos produtos do Brasil, M éxico, Canadá e A rgentina, atingem $95 \%$ do total da região. Se forem adicionados Colômbia, Venezuela, Peru e Chile, chega-se a 99\%. O u seja, um grupo de 9 países detém a produção, enquanto os países restantes (25) têm $1 \%$ do PIB dos 34 que fazem parte da Alca. M as isso não é tudo, pois as desigual dades entre os 9 países também são muito grandes. 0 Brasil apresenta o segundo maior PIB das Américas, $7,4 \%$, equivalendo a um décimo do PIB norte-americano.

Samuel Pinheiro Guimarães, embaixador brasileiro, ao analisar as estratégias militar, político-ideológica e econômica norte-americana para os países da América Latina, e especialmente o Brasil, elucida:

Do ângulo militar, essa estratégia visa colocar sob "protetorado" militar americano os Estados da América Latina, por meio de acordos que dificultem ou impossibilitem o desenvolvimento de tecnologias avançadas, que são 
muitas vezes, pela sua natureza, duais (como uso militar e civil), que reduzam seus armamentos convencionais e, por último, que confiem às suas $F$ orças A rmadas apenas o papel de guardiões da ordem interna, transformando-as em forças policiais.

$\mathrm{Na}$ área econômica, os principais instrumentos da "estratégia de M iami" são a pressão pela adoção de políticas neoliberais de reorganização econômica, que "reduzam" (e enfraqueçam) os Estados e desr egulamentem as economias e, finalmente, pela cristalização jurídica da abertura comercial e financeira, por meio de um tratado de criação de uma área de livre comércio das Américas, a Alca.

0 objetivo econômico norte-americano éo de estabelecer um território econômico único nas Américas, com livre circulação de bens, serviços e capitais, porém sem livre circulação da mão-de-obra, em especial aquela de menor qualificação, e, gradualmente, fazer adotar 0 dólar como moeda hemisférica, cuja emissão e circulação ficariam sob exclusivo controle norte-americano, ao contrário do euro, em que o controle da moeda é exercido de forma col etiva, pelos Estados da União Européia. Alguns dos objeti vos intermediários ou parciais na execução da estratégia americana e que poderiam ser visados gradual mente seriam: (...) obter concessões, anteci pando o que seria objeto de negociação comercial na futura Rodada do M ilênio da OM C e nas negociações sobre capitais do acordo multilateral de investimentos, ora em elaboração na O CDE (Guimarães, 2000).

É o que confirmam al gumas das declarações de governantes dos EU A, a exemplo da que segue: 0 nosso objetivo com a Alca é garantir para as empresas norte-americanas 0 controle de um território que vai do Pólo Ártico até a Antártida elivre acesso, sem nenhum obstáculo ou dificuldade, de nossos produtos, serviços, tecnologia e capital entre todo o $\mathrm{He}$ misfério! (General Colin Powell, Secretário de Estado do Governo Bush. Para Entender a Alca, 2002).

\section{0 contexto da Alca: o processo de globalização}

$\mathrm{N}$ a realidade, para se compreender a Alca é preciso caracterizar o processo de globalização em curso, pois a constituição de uma área de livre comércio sob a direção dos EU A re- presenta uma síntese da "mundialização do capital" e da "ultraliberalização". Essa nova configuração do capitalismo, a "acumulação flexível" (H arvey, 1990), impõe a lógica determinada pela financeirização, sob o comando do capital financeiro, cuja rapidez, volatilidade e ferocidade exigem a total liberdade de circulação, derrubando todos os limites e barreiras, que encontram perfeita ressonância e sustentação no model o neoliberal, que se tornou hegemônico em todo o mundo.

N este contexto de gl obalização e de aplicação de políticas neoliberais, é possível afirmar que nas três úl timas décad as se realizaram al gumas das principais ten dências do desenvolvimento do capital, já formuladas por M arx, quais sejam: 1) a livre mobilidade dos capitais, o derrubamento efetivo de fronteiras com a intensificação da internacionalização dos investimentos, propiciada, de um lado, pelo desenvolvimento tecnológico no campo das telecomunicações e, de outro, pela desregulamentação dos mercados estabel ecida pelas políticas neoliberais aplicadas pelos governos. Trata-se de uma ação do capital em que não há qual quer comprometimento com o desenvolvimento nacional dos países a que se destinam as suas aplicações; 2) a concentração e centralização de capitais atingi ram um patamar em que as empresas - agora transnacionais - têm o poder de decidir, sem a mediação do estado, sobre os rumos das economias nacionais dos países. Atualmente cerca de $1 / 3$ do comércio exterior se dá através dos Investimentos Externos Diretos (IED ), ou seja, en tre as empresas sem a participação do Estado; 3) uma fragilização e perda de poder e soberania dos estados nacionais periféricos dificultam fortemente a aplicação de políticas de defesa dos interesses nacionais.

É nesta mesma direção que o sociólogo francês Pierre Bourdieu (1998) afirma: Todo o universo da produção, material e cultural, pública e privada, é assim arrebatado num vasto processo de precarização, inclusive com 'a desterritorialização da empresa': ligada até então a um Estado-nação ou a um lugar (Detroit ou Turim, para a indústria automobilística), esta tende cada vez mais a dissociar-se dele, com o que se chama de "empresa-rede", que se articula na escala de um continente ou do planeta inteiro, conectando segmentos de produção, con hecimentos tecnológicos, redes de comunicação, percursos de formação di s- 
persos entre lugares muito afastados (Bourdieu, 1998).

0 desenvolvimento dessas ten dências foi ancorado num conjunto de políticas que servem como fio condutor da ação dos governos cuja atuação tem se pautado na defesa dos interesses das grandes corporações e empresas transnacionais. 0 centro de todas essas políticas éa defesa intransigente do "livre mercado", o que significa, na realidade, elevar o mercado à condição de "sujeito", como aquel e que exige, que determina, que "reina". O bserva-se nesta "profissão de fé" ao mercado a forma, talvez mais evoluída, de fetichismo da mercadoria. É como se o mercado assumisse vida própria e adquirisse tamanho poder sobre os homens que os deixa encantados. 0 culto ao mercado passa a ser a religião que justifica toda e qualquer ação dos homens ou dos governos que aplicam as políticas exigidas pelo deus-mercado.

Dentre as políticas implementadas a partir dessa diretriz maior, pode-se destacar: 1) os processos de privatização das empresas estatais ou mesmo dos serviços públicos prestados pelo Estado, a exemplo da saúde e da educação; 2) a desregulamentação do mercado de trabal ho, pois o Estado não deve mais mediar nem garantir os direitos dos trabal hadores, já que as disputas devem se dar livremente entre empregadores e empregados; 3) a ausência de uma política industrial na perspectiva do desenvolvimento nacional, pois esta é incompatível com a necessária mobilidade dos capitais; e 4) o desmantelamento de políticas sociais/públicas por parte do estado, que não pode mais ter esse compromisso, já que conflitará com os interesses do mercado. Essas passam a ser geridas e financiadas pelo Banco M undial, que decide, acima dos governos nacionais, qual o segmento da população que deve ser "focado" para ser assistido, através dos seus programas de financiamento aos países periféricos.

Essas políticas expressam a nova configuração assumida pelo sistema capital ista nas últimas três décadas. Trata-se da acumulação flexível que, segundo Harvey (1992), é um novo regime de acumulação, que vem se constituindo numa transição histórica, desde o início dos anos 70, marcada pela crise do fordismo. Essa transição, segundo o autor, tem a flexibilização da produção e do trabalho como mudanças mais visíveis, que só podem ser explicadas por um outro fenômeno, qual seja, o florescimento e transformação extraordinários dos mercados financei ros, com a gradativa hegemonia do capital financeiro no desenvolvimento do capitalismo na atual conjuntura.

Assim, no âmbito do trabal ho e, portanto, da relação social fundamental do sistema capitalista, a flexibilização assume uma centralidade inquestionável e transforma-se na estratégia principal do capital nos tempos de globalização e da liberalização dos mercados.

\section{0 quadro da flexibilização do trabalho, do (des)emprego e da saúde dos trabalhadores}

De acordo com Bourdieu (1998), "a precariedade está hoje por toda a parte" e a flexibilidade é uma "estratégia de precarização", inspirada por motivos econômicos e políticos, sendo o produto de uma vontade política e não de uma fatalidade econômica dada pela mundialização. Assim afirma que:

"A precariedade se inscreve num modo de dominação de tipo novo, fundado na instituição de uma situação generalizada e permanente de insegurança, visando obrigar os trabalhadores à submissão, à aceitação da exploração. A pesar de seus efeitos se assemelharem muito pouco ao capitalismo selvagem das origens, esse modo de dominação é absolutamente sem precedentes, motivando alguém a propor aqui o conceito ao mesmo tempo muito pertinente e muito expressivo de 'flexploração'. Essa palavra evoca bem essa gestão irracional da insegurança, que, instaurando, sobretudo através da manipulação or questrada do espaço da produção, a concorrência entre os trabalhadores dos países com conquistas sociais mais importantes, com resistências sindicais mais bem organizadas - características ligadas a um território e a uma história nacionais - e os trabalhadores dos países menos avançados socialmente, acaba por quebrar as resistências e obtém a obediência e a submissão, por mecanismos aparentemente naturais, que são por si mesmos sua própria justificação" (Bourdieu, 1998, grifos nossos).

É este o quadro constituído pelo processo de globalização e de liberalização. O s resultados constatados da reestruturação em curso são mundializados: 0 aumento do desemprego em todos os países do mundo, atingindo 
taxas inéditas; a precarização das condições de trabalho e da saúde dos trabalhadores, por conta, em primeiro lugar, da violenta intensificação do trabal ho, propiciadas pelas novas tecnologias e pelas políticas de gestão/organização do trabalho; a precarização dos contratos (flexíveis) de trabalho, a flexibilização dos direitos trabalhistas e sociais, através das mudanças na legislação, a fragilização dos sindicatos e das lutas dos trabal hadores, que se encontram divididos, segmentados, desvalorizados, em função da insegurança permanente. U m quadro que indica uma situação de regressão social em todo o mundo, inclusivenaqueles países mais desenvolvidos e, em particular, na maior potência do mundo: os EUA.

No caso brasileiro, a precarização tem se refletido no aumento das situações de riscose de insegurança, gerando o aumento dos acidentes de trabalho, que, no âmbito da indústria, vêm ocorrendo principalmente com os trabalhadores subcontratados, em geral os menos qualificados e treinados, com longas jornadas, sem direitos, sem cobertura de planos de saúde, tratados como trabalhadores de "segunda categoria" e, nessa condição, a flexibilização atinge as suas próprias vidas com uma precarização quase sem limites da saúde.

Para os demais trabalhadores que ainda permanecem numa condição menos instável, que são contratados diretamente pelas empresas, está permanentemente presente a possibilidade do desemprego. E, para evitáIo, adaptam-se às estratégi as das empresas, que para obterem os certificados das ISOS que normatizam as condições de segurança e saúde do trabalho, precisam cumprir as metas definidas, não interessa a qual preço. Assim, torna-se cada vez mais comum o não registro de acidentes ou o não afastamento por problemas de acidentes ou saúde, já que os trabal hadores são pressionados por suas gerências a cooperarem no cumprimento das metas e, a cada registro ou afastamento, eles se sentem rompendo o compromisso e a cooperação e, desta forma, colocan do em risco a sua permanência na empresa.

No que se refere ao desemprego, convivese hoje com as maiores taxas da história do país. $\mathrm{N}$ a região mais industrializada e mais desenvolvida - São Paulo - atinge-se 19\% de taxa de desem rego, o que representa cerca de um milhão e oitocentos mil pessoas sem emprego. A Região M etropolitana de Salvador tem a taxa mais alta do país: $25 \%$. Para além dos números, os desempregados se encontram nessa situação involuntariamente e se sentem impossibilitados para o trabalho, além de sofrerem todo tipo de discriminação social. Tem crescido o número de casos de suicídios e de problemas de saúde mental entre os desempregados. E, para fugir dessa condição "... é melhor ter qualquer emprego do que nenhum..."

\section{0 que significa a Alca neste "mundo globalizado"? As principais implicações}

A Alca, além de significar uma síntese da globalização e da ultraliberalização, não é uma proposta inovadora. $\mathrm{N}$ a realidade, já existe uma área de livre comércio que está vigorando desde 1994, o N afta (N orth American Free Trade Agreement - Acordo de Livre Comércio N orte-Americano), que reúne Estados U nidos, Canadá e M éxico e que já funciona de acordo com as mesmas regras que estão sendo propostas para a Alca. D esta forma, a Alca éuma extensão do $\mathrm{N}$ afta e, nesta medida, analisar os resultados já demonstrados deste acordo permite avaliar o que pode ser desencadeado em nosso país e, em especial, aos trabalhadores de todos os países americanos.

O N afta e a Alca oficializam, ao contar com o aval dos governos nacionais, um acordo que dá total liberdade ao capital - e éisso quesignifica o "Iivre comércio" - e nenhuma mobilidade ou liberdade ao trabalho. Isto é, os livres investimentos e negócios para aqueles que se impõem através do mercado, de sua capacidade competitiva que tem sido hegemonizados pelos capitais dos EUA, protegidos por regras já definidas e que não serão alteradas num possível acordo. É isto que se constata no funcionamento do $\mathrm{N}$ afta.

Assim, as principais conseqüências da Alca já podem ser visualizadas, sendo a reprodução e ampliação daquelas já constatadas para os trabal hadores dos EUA, Canadá e México. Há um processo de precarização do trabalho e da vida, que se intensificou e se ampliou, após o acordo. E, dada a desigualdade entre os três países, em especial o M éxico 
frente aos EU A e Canadá, o agravamento dos problemas sociais na sociedade mexicana é muito grande. É o que demonstram os dados: 0 aumento do desemprego (um crescimento de $20 \%$ em 4 anos), dois terços dos trabalhadores não recebem nenhum tipo de benefício e direito (seguridade social, pagamento de férias, feriados, etc); crescimento do trabal ho infantil (mais de 10 milhões de crianças trabalhando).

U m dos "pilares" da economia mexicana é a indústria de montagem, através da instalação das "maquiladoras", que como o nome indica, são empresas de montagem e acabamento de produtos para exportação para os EU A e outros países. $\mathrm{N}$ a sua gran de maioria são norte-americanas, mas há japonesas, canadenses e coreanas. Elas representam $15 \%$ do valor da produção da indústria manufaturei ra mexicana e são responsáveis por 50 por cento de todas as exportações do país (Azevedo, 1997).

Começaram a se instalar em 1965, lentamente, mas em novembro de 1994, totalizavam 2.163 e empregavam 497 mil trabal hadores. Com a crise do M éxico (dez/1994) 28 mil pequenas e médias empresas mexicanas encerraram suas atividades, dois milhões de empregos desapareceram, mas as maquiladoras não sofreram nenhum abalo. Com o N afta, essa situação confortável e privilegiada das referidas empresas ficou ainda melhor, pois as barreiras alfandegárias foram eliminadas, atraindo mais empresas para o M éxico. Em 1997, calcula-se que eram 3.650 maquiladoras, empregando por volta de 1 milhão de trabalhadores. Mas em que condições? 0 preço da força de trabal ho éum dos mais baixos do mundo. Em 1996, o salário pago por hora era de 1,47 dólares. Além disso, a jornada de trabal ho, que é uma das mais longas, e a ausência de direitos trabal histas e/ ou o acobertamento pelo Estado do não cumprimento daqueles existentes são fatores de estímulo contínuo à chegada de novas empresas ( Azevedo, 1997).

O s relatos apresentados pela reportagem "O muro americano", de Carlos de Azevedo, na Revista Reportagem/O ficina de Informações, são muito elucidativos. De acordo com informações obtidas com a Casa de La M ujer, que defen de os direitos das mulheres trabaIhadoras, $66 \%$ dos empregados das maquiladoras são mulheres. 0 depoimento da coordenadora dessa organização - Carmen Valadez - revela as condições de trabalho a que são submetidas:

0 ritmo de produção é extenuante (resultado dos programas de "qualidade" ); há falta de segurança, falta de proteção à saúde, o que leva à contaminação por produtos químicos. Já comprovamos, através de uma investigação realizada pela organização internacional H uman Rights W atch, que a discriminação contra trabalhadoras grávidas é prática generalizada, assim como o abuso sexual. (...) As jornadas de trabalho são variáveis segundo as necessi dades e conveni ências da empresa, freqüentemente sem pagamento de horas extras. Grande número de maquiladoras são têxteis e as costureiras têm os piores salários: cerca de 4 dólares por dia. 0 s outros ganham de 5 a 6 dólares por dia em média. $\mathrm{E}$ a alta rotatividade é a regra: é comum trabal hadores que em poucos anos já passaram por dez a quinze empresas. São demitidos a qualquer momento, sem motivo, e não têm direito à in denização. A alta rotatividade visa manter ou reduzir ainda mais o baixo padrão salarial. I sso é 0 que se chama desregulamentação do mercado de trabalho (Azevedo, 1997).

Quando os trabalhadores organizam um movimento de reivindicação por melhorias em alguma empresa, esta responde com a ameaça de transferência para outra região. $E$ há casos de fechamento de empresas e a transferência para cidades "mais calmas", onde não haja qual quer resistência operária. E contam, normalmente, com o apoio do poder público.

Segundo dados oficiais do M éxico, o PIB está crescendo, as exportações atingiram 100 bilhões de dólares e, entre 1993 e 1997, o número de empregos cresceu $3 \%$ ao ano, o que representa a criação de 1 milhão de novos empregos a cada ano. No entanto, as estatísticas sobre a emigração continuam muito altas e as estratégias de controle das fronteiras se tornam cada vez mais sofisticadas.

$\mathrm{N}$ a realidade, o que se constata é a livre mobilidade para os capitais. Em contrapartida há o rigoroso controle das fronteiras para impedir a migração mexicana que, apesar do anunciado crescimento do emprego, não se esgotou. No período de 1990 a 1996, entraram nos EUA 1,9 milhão de mexicanos, uma média de 315 mil por ano. Calcula-se que desses, cerca de 630 mil eram ilegais.

Em outubro de 1994, foi criada a O peração Guardiã para controlar a imigração ilegal na região de San Diego e Tijuana. Em seguida, veio a O peração Rio Grande, para cuidar da 
fronteira do Texas. São iniciativas de “(...) um plano estratégico de prevention through deterrence ( prevenção por meio da intimidação) anunciado pel o presidente Clinton em julho de 1994 e cujo objetivo é conseguir o controle efetivo dos 3 mil quilômetros de fronteira com o M éxico. São al tos investimentos no uso de alta tecnologia (aparel hos de infravermel ho de longo alcance, câmeras de TV e monitores com capacidade para "ver" no escuro, sensores, luzes, rádios de alta potência e sistema de identificação biométrica), combinada com o treinamento de agentes especializados em várias funções, que assumem a "proteção da fronteira" e, assim, cumprem o papel que 0 governo norte-americano Ihes destina: os guardiões do capital.

Ainda de acordo com os próprios trabaIhadores mexicanos, a migração continua porque a condição de trabal ho e de salário é extremamente precária e, mesmo assim, não há empregos para todos. A desigual dade entre EUA e M éxico é extremamente grande: enquanto o salário médio nas maquiladoras é de 4,5 dólares por dia (uma jornada de 9 horas), nos EUA, é possível ganhar 5 dólares por hora, ou seja, 10 vezes mais.

Essa necessária descrição da situação do
M éxico não deve ocultar o quadro de precarização dos trabal hadores noutros países. N os EU A, 7 entre cada 10 empregos criados nos últimos 10 anos são precários, ou seja, por tempo determinado, parcial, sem cobertura social, e sem direitos. A redução dos níveis salariais tem levado a um achatamento dos salários, reduzindo a capacidade de compra dos trabalhadores. U ma situação de precarização que não atinge somente os migrantes, como sempre se soube, mas que agora se esten de para os americanos que vivem do trabalho.

É esta a realidade criada pelo $\mathrm{N}$ afta e que será amplificada pela Alca. 0 "lugar" que 0 M éxico hoje ocupa no Acordo de Livre Comércio N orte-Americano - ressalvando-se as diferenças de diversas naturezas entre os dois países - poderá ser ocupado pelo Brasil na Área de Livre Comércio das Américas.

$\mathrm{N}$ a sua essência a Alca pretende, através de um Acordo entre os 34 países, outorgar às corporações transnacionais direitos especiais para o uso de arbitragem internacional de forma secreta e sem controle público, acima e por cima dos estados nacionais, obrigando os governos a tratarem os investidores estrangeiros da mesma forma que os nacionais. É o que já vem ocorrendo no $\mathrm{N}$ afta, pois as em-

\section{Quadro 1}

Levantamento de processos movidos por empresas contra governos para obter indenizações e suspen são de medidas protecionistas governamentais baseados em dispositivos do NAFTA - Período 1998/1999.

\begin{tabular}{|c|c|c|c|}
\hline Governo acionado & Empresa/Sede & Indenização pretendida & Aspectos \\
\hline Canadá & Ethyl Co/EUA & US\$250 milhões & Aditivo/gasolina neurotóxico \\
\hline Canadá & S.D.Myers/EUA & US\$30 milhões & Resíduos contaminados PCBs \\
\hline Canadá & SunB eltWaterlnc/EUA & $\begin{array}{l}\text { Entre US\$1 bilhão } \\
\text { eUS } \$ 10 \text { bilhões }\end{array}$ & Exportação água \\
\hline Canadá & Pope\&Talbot/EUA & US\$510 milhões & Quotas de exportação madeira \\
\hline EUA & LoewenGroup/Canadá & & Tratamento discriminatório \\
\hline EUA & M ethanex Corp/Canadá & US\$970 milhões & Aditivo M TBE cancerígeno \\
\hline M éxico & M etalclad//EUA & US $\$ 90$ milhões & Proibição de despejo de resíduos \\
\hline M éxico & Waste $M$ angementInc/EUA & US\$60 milhões & M anejo resíduos sólidos \\
\hline M éxico & Desona/EUA & US\$14 milhões & Manejo resíduos \\
\hline M éxico & CEM SA/EUA & US\$50 milhões & Questões tributárias \\
\hline EUA & M ondev International/Canadá & US\$16 milhões & Limites à expansão imobiliária \\
\hline
\end{tabular}

Fonte: Sistematização baseada em levantamento realizado por M ichelle Swennarchuk (Swenarchuk, 1999 apud La inversión, las finanzas y la deuda en las Américas, disponível em <www.asc-hsa.org/analisis.html>) 
presas têm se apoiado no Artigo 11 do Acordo, concernente à proteção dos investimentos estrangeiros, no que tange a "expropriação ou nacionalização", que obrigaria os governos a cobrir os prejuízos e/ou perdas das empresas atingidas. Utilizando-se desse artigo, questionam as políticas de proteção ambiental e de saú de humana, argumentan do que as limitações impostas por legislações dessa natureza implicam um tipo de "expropriação", já que elas deixariam de ganhar, perdendo oportunidades de produção e de mercado.

É o que indica um levantamento realizado pela advogada ambientalista M ichelle Swenarchuk, até 0 ano de 1999, que registra algumas disputas entre empresas estrangei ras e os governos nacionais, com base em dispositivos do N afta (Quadro 1).

Premonitório, a esse respeito, é o caso da Ethyl. Essa empresa sediada nos EU A apóia-se em dispositivo muito menos favorável do que os do AMI, os do A cordo de Livre Comércio N orte-Americano (NAFTA), para reclamar U S\$251 milhões (...) ao governo do Canadá. Em abril de 1997, Ottawa tinha proibido o uso de um aditivo à gasolina, denominado M M T, uma neurotoxina suspeita de prejudicar os dispositivos antipolui ção dos automóvei s. A Ethyl, única produtora do M M T, propôsuma ação contra o governo canadense, argüindo que a proibição de seu uso no Canadá equivalia a uma expropriação de bens da companhia (Wallach, 1998).

Como bem observou Wallach, então, "por incrível que pareça, o processo vai ser julgado". E foi! Julgado em 1998, o estado canadense foi condenado a pagar, com os recursos dos contribuintes canadenses, a indenização de US\$13 milhões e a suspender a proibição, configurando um nítido instrumento de transferência de recursos públicos para empresas privadas e a anulação do papel do estado na proteção e segurança de sua população (justamente naquele país que tem apresentado o melhor IDH no ranking internacional!).

Tais iniciativas se inscrevem num processo de sucessivas tentativas, orquestradas, para desregulamentar as atividades de grandes empresas no que concerne aos recursos naturais e o meio ambiente, às conquistas sociais em termos de condições de trabalho, de seguridade social, e aos setores estratégicos para a soberania nacional e serviços de interesse público, dentre outras.

Vale ressaltar o ensaio com o AM I - Acor- do Multilateral sobre Investimentos - que estava sendo negociado desde 1995 na OCDE (O rganização para a Cooperação e D esenvolvimento Econômico), à revelia das populações concernentes e de alcance mundial. Foi colocado em latência devido aos movimentos sociais que o rechaçaram eà retirada da França das negociações em 1998.

O capítulo-chave do tratado se intitula "Direitos dos investidores". N ele figura o direito absoluto de investir - comprar terras, recursos naturais, serviços de tel ecomunicações ou outros, divisas - nas condições de desr egulamentação previstas pelo tratado, isto é: sem nenhuma restrição. O s governos têm a obrigação de garantir a 'plena fruição' desses investimentos. N umerosas cláusulas prevêem indenizações aos investi dores e às empresas, no caso de intervenções governamentais suscetíveis de restringir a capacidade de obterem lucro com os investimentos. Em particular, se os investidores ou investimentos sofrerem o 'efeito equivalente' a uma 'expropriação mesmo indireta'. Assim, nos termos do acordo, a 'perda de oportunidade de lucro sobre o investimento seria um tipo de prejuízo suficiente para dar di reito à indenização do investidor'.

As regras relativas às expropriações e indenizações são os dispositivos mais perigosos do AM I. Elas conferem a cada empresa ou investidor estrangei ro o di reito de contestar praticamente não importa que política ou ação governamental - desde as 'medidas fiscais' às di sposições em matéria de 'mei o ambiente'; da 'Iegislação do trabal ho' às normas de 'proteção ao consumidor' e ameaças potenciais sobre lucros. Portanto, os estados - que praticam, em toda parte, cortes claros nos programas sociais - são chamados a aprovar um programa mundial de assistência às empresas transnacionais (Wallach, 1998 disponível em www.diplo.com.br).

A latência do $\mathrm{AMI}$, a realidade do $\mathrm{N}$ afta e a ameaça da Alca representam grande retrocesso histórico - face aos avanços generalizados e diferenciados nos diversos países durante as décadas precedentes, do capitalismo fordista regulado e administrado pelo estado, com relativo e limitado, porém existente, espaço de pacto social. N essa fase das sociedades ocidentais fordistas centrais e periféricas foram adotadas diversas políticas macro-reguladoras do capital e do trabalho, exemplificadas através das políticas fiscais, monetárias, trabalhistas e ambientais dentre outras, criando 
no plano societal redes de seguridade e segurança social, mais ou menos avançadas, que significaram parâmetros importantes diante de uma voraz acumulação do capital, estabelecendo-se o reconhecimento de limites físicos ao uso de seres humanos no trabal ho e ao caráter ambiental predatório do fordismo fossilista ainda vigente. Atualmente caem as regulações sociais e políticas, mas as bases materiais e reais que as suscitaram permanecem intocadas, ou melhor, aprofundadas.

Essas regulações limitavam as ações de grandes empresas ao tempo em que a visibilidade de seu caráter predatório tornava-se apesar das dificuldades de registro e acesso às informações concernentes - cada vez mais inconteste. Expressões tais como o aumento da gravidade de grandes acidentes industriais no mundo, de seus custos econômicos, ônus político e social foram aliviados e/ou invisibilizados - não com a busca determinada e eficaz denovos padrões de produção e consumo menos predatórios e mais limpos - mas pela transferência de plantas industriais de al to risco para países periféricos estratégicos e mais permissivos em termos de proteção da saúde de trabalhadores e meio ambiente (tais como M éxico, Brasil, Índia). Esse mecanismo, embora desonere países centrais, é ainda insuficiente elimitado pelas regulamentações existentes. M ecanismos de burlá-las, tais como a 'transferência de riscos entre povos' e a 'terceirização' - criando categorias de trabaIhadores discriminados por diferentes políticas de gestão (contratação e remuneração, condições de trabal ho e segurança) - não têm sido suficientes para aplacar o objetivo deliberar o capital de todas as amarras e limites sociais e políticos. N esse processo e contexto surgem os tratados internacionais de comércio, e muito mais, passando por cima das sociedades, enfraquecen do os estados periféricos, buscando estabel ecer e legitimar sociedades sem perspectivas de eqüidade social, sem seres humanos no trabalho, sem indivíduos cidadãos, sem ... sem ... A ssim surge o $\mathrm{N}$ afta, seguido pela tentativa de gl obalizá-lo com o AM I, e a Alca. N a verdade, o N afta e a Alca são antecipações históricas do AM I em áreas geopolítico-econômicas mais restritas, sob o controle e hegemonia norte-americana mais direta.

\section{Divisão internacional dos riscos,}

\section{dumping social e ambiental}

A importância destes tratados precisa ser considerada sob a perspectiva da agu dização dos problemas concernentes ao trabalho, saúde e meio ambiente. Estes mantêm e perenizam os padrões de produção (e de consumo) do fordismo fossilista ambiental mente predatório (Altvater, 1995), assentados em recursos fósseis não renováveis - particularmente 0 petróleo, até então. A 'centralidade do trabaIho' eo eixo energético do 'petróleo' ainda são vitais para o sistema de acumulação hegemônico. As bases materiais e reais do fordismo fossilista, que suscitaram as regulações fordistas agora em cheque, permanecem intocadas, ou melhor, aprofundadas, como bem expressam os recentes episódios das guerras do Golfo, da invasão do Afeganistão e do holocausto em curso no Iraque.

$\mathrm{N}$ o tocante aos grandes acidentes industriais no mundo, pesqui sas diversas têm demonstrado o seu agravamento e transferência para os países periféricos desde meados da década de 1970 (Castleman, 1996; ThébaudM ony, 1990; Porto, 1994; Glickman et al. 1992 apud Freitas, 1996; M aimon, 1995). Sobre este terreno de transferência de riscos entre os povos se desdo bram os tratados que tendem a reforçar a fragilidade dos países periféricos nesta rede de relações muito desi guais e configurar a possibilidade de legitimação de dumping ambiental e social como estratégia decompetitividade internacional.

Ademais, estudos locais revelam tendências ao aumento da freqüência de acidentes industriais com impactos ambientais, a exemplo dos acidentes registrados pela C etesb em São Paulo/Brasil, entre as décadas de 1970 e 1990, ou ainda, a transferência de riscos para trabalhadores terceirizados, a exemplo do caso do Pólo Petroquímico de Camaçari/Bahia/Brasil, no período de 1989 a 1993, no qual foram constatadas proporções crescentes de acidentados terceirizados (Franco, 1997).

No caso brasileiro, convém relembrar dois instrumentos que, na verdade, anteciparam a Alca, eque tendem, se mantidos, viabilizados e/ ou consumados politicamente, a reestruturar o imaginário social apagando 'referenciais históricos' quanto ao 'trabalho' e à depredação do 'meio ambiente' no país. 0 primeiro diz respeito à suspensão por M edida Provisória (M P no1.710) da Lei de Crimes Ambientais (Lei 9.605/98) no país por 10 anos, poste- 
riormente reduzidos, durante o governo FHC.

$O$ segundo diz respeito ao processo de flexibilização do trabalho via reforma trabalhista em curso. Trata-se da proposta de reforma do artigo 618 da CLT, encaminhada ao Congresso pelo governo $\mathrm{FHC}$, que estabelece a primazia dos acordos col etivos entre sindicatos de trabalhadores e sindicatos patronais sobre as normas da CLT. Esta proposição foi retirada pelo atual governo e remetida à discussão no Fórum N acional do Trabalho. No atual contexto de desemprego, de "gestão pelo medo" (Déjours, 1999) e de fragilidade sindical, torna-se, no mínimo, temerário flexibilizar a regulamentação do trabalho nesta direção, que, sem dúvida, resultaria em aviltamento daqueles que vivem do trabalho assaIariado. A Alca tende a aprofundar o proble$\mathrm{ma}$, caso viabilize o nivelamento por baixo do mercado de trabalho na América Latina.

A reforma trabalhista proposta prevê a garantia de direitos pela Constituição ou por normas de segurança que, contudo, podem ser flexibilizados (negociados) em termos de 'quantidade' e 'modalidades' de concessão do benefício. Isto é, seriam "mantidos" e, simultaneamente, sujeitos à negociação num jogo de dados viciados (mercado de trabalho abarrotado e sindicatos fragilizados), históricos direitos sociais conquistados em defesa da vida dos indivíduos no mundo do trabalho. Assim, a duração da jornada de trabalho, a hora extra; o 13o salário, a redução salarial, os pisos sal ariais, o tempo de licença à gestante e a licença maternidade, o pagamento de aviso prévio, as férias de 30 dias, os adicionais de insalubridade e de hora noturna podem ser 'flexibilizados' e 'até abolidos' em negociação coletiva.

Riedel, advogado trabalhista, elucida o alcance dessas mudan ças:

"O governo FHC dourou a pílula ao apresentar a reforma da CLT ao Congresso. Os direitos da CLT estão assegurados na Constituição de 1988. Esses direitos estão todos no artigo 70, mas todos como princípio, como garantia, não como quantificação. Exemplo: a Constituição assegura que o salário mínimo deve corresponder àquilo que o trabalhador precisa para se alimentar, morar, prover os serviços de educação, saúde, tran sporte etc. A lei ordinária quantifica essas necessidades e diz, hoje, que o mínimo éde $R \$ 200,00$. Está se propondo que a lei ordinária passe pa- ra a convenção coletiva a competência para quantificar o direito assegurado na Constituição. Pode a conven ção coletiva quantificar em menos de $R \$ 200,00$ ? Pode, pois continua a garantia legal do direito ao mínimo. M as a convenção coleti va pode chegar à conclusão de que bastam $R \$ 180,00$ para satisfazer as necessidades mínimas de um trabalhador. Não é preciso acabar com o direito de férias, mas pode se convencionar que a quantidade não será mais de 30, mas de 20 ou 15 dias. As pessoas precisam estar conscientes disso (Primeira Leitura, 2003. Grifos nossos).

Vale considerar ainda a questão do salário mínimo no Brasil, um referencial e parâmetro para as remunerações no país. A reforma proposta ou a Alca serão plantadas num terreno já consolidado de perda progressiva do seu poder de compra. A deterioração do salário mínimo, ininterrupta, prevaleceu desde a década de 1960/70 - período de substituição de importações e do milagre brasileiro, pari passu aos notáveis crescimentos do PIB - permanecendo até hoje. Assim, conforme Ferreira (1993), a evolução do SM entre as décadas de 1950 e 1980 permite constatar, em termos de índices, que o seu valor real em 1980 correspondia à metade do salário de 1952. Entre 1989 e 1999, o salário mínimo continua perdendo poder aquisitivo, alcançando seu menor valor real no início de 1995.0 reajuste de $42,86 \%$, concedido em maio do mesmo ano e os sucessivos aumentos reais nos anos seguintes repuseram parte dessa perda. No entanto, em 1999, o salário mínimo correspondia a somente 2/3 do seu valor em 1989 (Dieese, 2001).

I mportante instrumento para selar a mise-en-scène democrática e participativa, na possível efetivação da reforma trabal hista até então proposta, éa reforma sindical. Trata-se especificamente da possi bilidade real de pulverização sindical e de "des-empowerment" da classe que vive do trabal ho, caso prevaleça a pluralidade sindical proposta, ao invés da unicidade sindical vigente. M ais um mecanismo que viciaria o campo de forças das negociações entre capital etrabal ho. Tal fragilização - à moda japonesa - tende a ser acentuada, particularmente, no contexto histórico configurado desde os anos 90, caso se fortaleça a visão do neoliberalismo obreiro que apregoa a ilusão do tira o Estado que as forças sindicais livres resolvem tudo. Recorrendo, mais uma vez, a Riedel: $\mathrm{N}$ ão resolvem. $\mathrm{E}$ elas 
A ofensiva dos governos neoliberais, as investidas do governo dos EU A reafirmando a sua posição de gen dar me do mundo, numa atuação claramente imperialista, bem como as articulações do Fórum de $D$ avos, que reúne as maiores instituições empresarias do mundo globalizado, em especial, as instituições financeiras, não ficaram sem respostas. Os movimentos antiglobalização vêm avançando a cada ano, com a realização de Fóruns M undiais, a exemplo do Fórum Social M undial (I, II e III) e dos mais diversos e plurais movimentos sociais e coletivos que ocorrem em todas as partes do mundo.

A riqueza desses movimentos está na sua pluralidade, no sentido de congregarem as mais diversas formas de organização: os sindicatos, movimentos sociais de todo tipo, do

\section{Referências bibliográficas}

Aliança Social Continental - ASC. La inversión, lasfinanzas y la deuda en las A méricas. Disponível em $<$ http:// www.asc-hsa.org/analisis.html>. Acesso em 16 jun 2002.

Altvater E 1995. 0 preço da riqueza. Editora da U niversidade Estadual Paulista, São Paulo.

Azevedo C 1997. 0 muro americano. Revista Reportagem/ O ficina de Informações, n. zero, dezembro.

Campanha Nacional Contra a Alca 2002. Para entender a ALCA. Edições Loyola. São Paulo.

Castleman B 1996. A migração de riscos industriais. Caderno CRH 24/25:41-67.

Bourdieu P 1998. Contrafogos. Ed. Jorge Zahar, Rio de Janeiro. 151pp.

Déjours C 1999. A banalização da injustiça social. Fundação Getúlio Vargas, Rio de Janeiro.

Dieese 2001. Os rendimentos do trabalho no Brasil. Dieese, São Paulo.

Franco T 1997 (org.). Trabalho, riscos industriais e mei o ambiente: rumo ao desenvolvimento sustentável? EDU FBA, Salvador.

Ferreira CG 1993. O fordismo, sua crise e o caso brasileiro. Cadernos do CESIT 13.

Freitas CM 1996. A cidentes químicos ampliados - incorporando a dimensão social nas análises de risco. Tese de doutorado. Escola Nacional de Saúde, Fiocruz, Rio de Janeiro.

Guimarães SP 2000. Quinhentos anos de periferia: uma contribuição ao estudo da política internacional.(2a ed.). Contraponto Editora-Editora da U niversidade/ UFRGS, Rio de Janeiro-Porto Alegre.

Harvey D 1992. Condição pós-moderna. Loyola, São Paulo.

M aimon D 1995. Responsabilidade ambiental das empresas brasileiras: realidade ou discurso? In Cavalcanti C (org.). D esenvolvimento e natureza: estudos para uma sociedade sustentável. Cortez-Fundação Joaquim N abuco. São Paulo-Recife.

Porto M FS 1994. Trabalho industrial, saúde e ecologia: avaliação qualitativa de riscos industriais com dois estudos de caso na indústria química. Tese de doutorado. COPPE/UFRJ. Rio de Janeiro.

Primeira Leitura n. 13. mar 2003.

Thébaud-M ony A 1990. L'envers des sociétés industrielles: approche comparative franco-brésiliènne. L'H armatan, Paris.

Wallach LM 1998. O novo manifesto do capitalismo mundial. Le Monde Diplomatique, fev.1998 . Disponível em < http://www.diplo.com.br>

Artigo apresentado em 12/4/2003

Aprovado em 26/10/2003

Versão final apresentada em 12/11/2003 